\title{
Clostridium scindens sp. nov., a Human Intestinal Bacterium with Desmolytic Activity on Corticoids
}

\author{
G. N. MORRIS,${ }^{1}$ J. WINTER, ${ }^{1}$ E. P. CATO,${ }^{2}$ A. E. RITCHIE,${ }^{3}$ AND V. D. BOKKENHEUSER ${ }^{1 *}$ \\ Department of Pathalogy, St. Luke's Hospital Center, New York, New York 10025'; Department of Anaerobic \\ Microbiology, Virginia Polytechnic Institute and State University, Blacksburg, Virginia 24061 ${ }^{2}$; and The National Animal \\ Disease Center, Ames, Iowa $50010^{3}$
}

\begin{abstract}
Clostridium scindens sp. nov., an obligate anaerobe with desmolytic activity, was isolated from human fecal flora. The desmolase, not associated previously with any specific intestinal microorganism, cleaves the carbon-carbon bond of 17-hydroxylated corticoids at $\mathrm{C17}-\mathrm{C20}$, thereby converting them to androstans (C19 steroids). In primary cultures on sheep blood agar plates, $C$. scindens forms minute, nonhemolytic colonies. The gram-positive rods $(0.5$ to 0.7 by 1 to $2.5 \mu \mathrm{m})$ are slightly curved. The rare oval terminal spores $(0.8$ to $2.0 \mathrm{\mu m}$ in diameter) are extremely difficult to demonstrate in Gram-stained smears. More than $40 \%$ of the cells are fimbriated. Neither a capsule nor flagella are present. D-Fructose, D-glucose, lactose, D-mannose, D-ribose, and D-xylose are fermented. The major fermentation products are acetic acid, ethanol, and hydrogen. The type strain is ATCC 35704 (Bokkenheuser strain 19).
\end{abstract}

In 1957, Nabarro et al. (14) noted increased excretion of urinary 17 -keto steroids in two of three patients who were receiving rectal infusion of cortisol for ulcerative colitis. The observation was confirmed by Wade et al. (22), who also demonstrated that side-chain cleavage of cortisol was suppressed by oral administration of neomycin, which implicated bacterial flora in the steroid transformation. Direct evidence of bacterial participation in the conversion was provided by Gustafsson (7) and Eriksson and Gustafsson (6), who demonstrated the in vitro conversion of cortisol to $5 \xi$-androstane- $3 \xi, 11 \xi, 17 \xi$-triol by human intestinal flora. In 1981, Cerone-McLernon et al. (5) investigated the conditions for desmolase activity of the fecal flora and showed that the concentration of converting organisms in feces was approximately $10^{6} / \mathrm{g}$.

Recently, Bokkenheuser et al. (1), using both dilution and replica plating techniques (12), succeeded in isolating a fecal organism that synthesizes steroid desmolase. This organism, a clostridium, has characteristics unlike those of described species. In the present study, we examined the growth conditions, morphological characteristics, and biochemical properties of this organism, for which we propose the name Clostridium scindens.

\section{MATERIALS AND METHODS}

Isolation. $C$. scindens (Bokkenheuser strain 19) was isolated from the fecal flora of a healthy human subject with media and techniques previously described (4).

Morphological characteristics. Examinations for Gram reaction, size, shape, and appearance were from 16- to 24-h cultures in supplemented peptone broth (Becton Dickinson and Co., Paramus, N.J.) or prereduced, supplemented brain heart infusion broth with cysteine (Scott Laboratories, Inc., Fiskeville, R.I.). Colonial morphology was determined on Columbia blood agar plates (BBL Microbiology Systems, Cockeysville, Md.). Electron microscopy was performed as previously described (1). Briefly, cells were harvested by centrifuging at 7,000 $\times g$ for $15 \mathrm{~min}$ and were dispersed in distilled water. The suspension was diluted in 0.2 to $0.4 \%$

\footnotetext{
* Corresponding author.
}

potassium phosphotungstate $(\mathrm{pH} 6.7)$ containing $0.05 \%$ bovine serum albumin and was applied to carboned collodionfilmed grids with a Vaponefrin-type nebulizer. The grids were examined immediately with an electron microscope (model EM-200; Philips Electronic Instrument, Mahwah, N.J.) operated at $60 \mathrm{kV}$ with double-condenser illumination and a 30- to 35-mm copper disk aperture in the objective.

Phenotypic characterization. Biochemical characteristics and fermentation products were determined as described previously (8). Biochemical tests were read after 7 days of incubation, Antibiotic susceptibility was tested by the brothdisk method $(8,23)$.

\section{RESULTS}

Strain 19 is an obligately anaerobic, chemo-organotrophic, gram-positive rod that forms endospores and therefore is a member of the genus Clostridium (20). It has characteristics unlike other described species in the genus (Table 1). For this new species we propose the name $C$. scindens.

Description of $C$. scindens. $C$. scindens sp. nov. (scin'dens [pronounced "skin'dens" or "sin'dens"'] L. part. adj. scindens-splitting, because it produces a desmolase) cells are nonmotile and stain gram positive. Endospores are terminal and wider than the vegetative cell. The spores are difficult to demonstrate microscopically but are observed in stains from chopped meat agar slants incubated at $30^{\circ} \mathrm{C}$ for 3 weeks. Cultures from egg yolk agar plates incubated anaerobically at $30^{\circ} \mathrm{C}$ for 7 days survive heating at $80^{\circ} \mathrm{C}$ for $10 \mathrm{~min}$ and treatment with absolute ethanol for $30 \mathrm{~min}$.

Electron microscopy. This strain showed considerable pleomorphism. Cells in the log phase of growth are rod shaped and slightly curved (about 0.5 to 0.7 by 1.0 to $2.5 \mu \mathrm{m}$ ) and occurred singly or in chains (Fig. 1). Mesosomes are prominent at the septae in larger dividing cells. Daughter cells usually share unequal amounts of cellular mass. Small coccus-shaped cells $(0.4$ to $0.6 \mu \mathrm{m})$ occasionally are observed. Cell walls separated from the cell are typically amorphous. More than $40 \%$ of the cells are fimbriated, with fimbriae of 3.0 to $3.5 \mathrm{~nm}$ in diameter. The fimbriae often are fascicled in clusters of 2 to $\mathbf{1 0}$ or more strands.

Colonial morphology. Colonies on anaerobically incubated blood agar plates (GasPak; BBL) are minute (little more than 
TABLE 1. Phenotypic characteristics that differentiate C. scindens from other species of Clostridum ${ }^{a}$

\begin{tabular}{|c|c|c|c|c|c|c|c|c|c|c|}
\hline \multirow[b]{2}{*}{ Characteristic } & \multicolumn{10}{|c|}{ Presence, absence, and prevalence of characteristic among ${ }^{b}$ : } \\
\hline & $\begin{array}{c}C . \\
\text { scindens }\end{array}$ & $\begin{array}{c}\text { C. } \\
\text { butyr- } \\
\text { icum }\end{array}$ & $\begin{array}{c}C . \\
\text { cello- } \\
\text { bioparum }\end{array}$ & $\begin{array}{c}C . \\
\text { clostri- } \\
\text { diforme }\end{array}$ & $\begin{array}{l}\text { C. coc- } \\
\text { leatum }\end{array}$ & $\begin{array}{c}C . \\
\text { nexile }\end{array}$ & $\begin{array}{c}C . \\
\text { oroticum }\end{array}$ & $\begin{array}{c}C . \\
\text { papy- } \\
\text { rosolvens }\end{array}$ & $\begin{array}{c}C . \\
\text { ramosum }\end{array}$ & $\begin{array}{l}\text { C. spi- } \\
\text { roforme }\end{array}$ \\
\hline Esculin hydrolyzed & - & + & + & + & + & + & + & + & + &,-+ \\
\hline Motility & - & + & + &,-+ & - & - & - & + & - & - \\
\hline Acid produced from: & & & & & & & & & & \\
\hline L-Arabinose & - &,$+ w$ & + & $\mathrm{v}$ & - & - & + & + & - & - \\
\hline Maltose & - & + & + &,$+ w$ &,-+ &,$- \mathrm{w}$ & + & - & + & - \\
\hline D-Ribose & + &,$+ w$ & + & $\mathrm{v}$ & - & - & + & + & v & - \\
\hline Sucrose & - & + & - & + & + &,$+ w$ & + & - & + & + \\
\hline D-Xylose & + & + & + & + & - & $w,+$ & + & + &,$- w$ & - \\
\hline
\end{tabular}

${ }^{a}$ Strains of these species produce acid from glucose, do not hydrolyze gelatin, and do not produce indole; principal products of fermentation are acetic acid and abundant hydrogen; no propionic, butyric, isobutyric, or isovaleric acid is produced.

$b+$, Reaction positive for 90 to $100 \%$ of strains (pH of sugars below 5.5); - , reaction negative for 90 to $100 \%$ of strains; w, weak reaction ( $\mathrm{pH} 5.5$ or higher); $\mathrm{v}, 40$ to $60 \%$ of strains positive. Where two reactions are listed, the first is the more usual and occurs in 60 to $90 \%$ of strains.

$0.1 \mathrm{~mm}$ in diameter) when first isolated. In subsequent subcultures on blood agar plates, two colony types are observed: a small, common type with a diameter of 0.3 to 0.7 $\mathrm{mm}$ and a rarer type with a diameter of 1.3 to $2.0 \mathrm{~mm}$. After repeated subculturing, the larger colonies became more common. All colonies are circular to slightly irregular, low convex, smooth, glistening, and greyish white with an entire periphery. Neither sheep nor rabbit erythrocytes are hemolyzed. The optimum temperature for growth is $42^{\circ} \mathrm{C}$; good growth occurred at 37 and $45^{\circ} \mathrm{C}$; growth is slow at $25^{\circ} \mathrm{C}$, and none occurs at $50^{\circ} \mathrm{C}$.

Broth growth. Growth in glucose broth is turbid, with a smooth sediment after incubation for $24 \mathrm{~h}$. A mucoid sediment formed after incubation for $48 \mathrm{~h}$.

Phenotypic reactions. D-Fructose, D-glucose, lactose, Dmannose, D-ribose, and D-xylose are fermented ( $\mathrm{pH} 4.9$ to 5.5). Hydrogen sulfide is detected in sulfide-indole-motility medium. Abundant gas is produced in peptone-yeast extractglucose $(1 \%)$ agar.

Amygdalin, L-arabinose, D-cellobiose, meso-erythritol, esculin, glycogen, myo-inositol, maltose, D-mannitol, Dmelezitose, D-melibiose, D-raffinose, L-rhamnose, salicin, D-sorbitol, starch, sucrose, and D-trehalose are not fermented. Gelatin, milk, and meat are not digested. Neither indole, lecithinase, lipase, nor catalase is produced. Nitrate is not reduced. Neither starch nor esculin is hydrolyzed.

The products of fermentation in peptone-yeast extractglucose broth are acetic acid and ethanol. Abundant hydrogen is produced. Pyruvate is converted to acetate; lactate is not utilized.

TABLE 2. Enzymatic activity of $C$. scindens on steroids and bile acids

\begin{tabular}{|c|c|}
\hline Type of substrate & Type of reaction \\
\hline $17 \alpha-$ Hydroxysteroids ${ }^{a}$ & $\begin{array}{l}\text { Side-chain cleavage and } \\
20 \text {-keto reduction }\end{array}$ \\
\hline 17-Deoxysteroids ${ }^{b}$. & 20-Keto reduction \\
\hline Bile acids & $\begin{array}{c}.7 \alpha \text {-Dehydroxylation and } \\
7 \beta \text {-dehydrogenation }\end{array}$ \\
\hline
\end{tabular}

a Cortisol, tetrahydrocortisol, cortisone, 11-deoxycortisol, 21deoxycortisol, and $17 \alpha$-hydroxyprogesterone.

${ }^{b}$ Deoxycorticosterone, corticosterone, 11-dehydrocorticosterone, progesterone, and $16 \alpha$-hydroxyprogesterone.

c $7 \alpha$-Dehydroxylation of cholic and cherodeoxycholic acids and $7 \beta$ dehydrogenation of ursodeoxycholic acid.
The guanine plus cytosine content of deoxyribonucleic acid as determined by the thermal melting point methods ( 9 , 13 ), is $45 \mathrm{~mol} \%$.

The type strain is susceptible to penicillin $\mathrm{G}(2 \mathrm{U} / \mathrm{ml})$ but resistant to chloramphenicol $12 \mu \mathrm{g} / \mathrm{ml})$, clindamycin $(1.6$ $\mu \mathrm{g} / \mathrm{ml})$, erythromycin $(3 \mu \mathrm{g} / \mathrm{ml})$, and tetracycline $(6 \mu \mathrm{g} / \mathrm{ml})$.

Enzymatic activity on steroids and bile acids. $C$. scindens synthesizes at least four enzymes active on steroidal substrates (24). The steroid desmolase cleaves the C17-C20 bond of a variety of $17 \alpha$-hydroxy steroids (Table 2 ). In the absence of a hydroxyl group at $\mathrm{C} 17$, the side chain could not be removed, but the $\mathrm{C} 20$ keto group of corticoids was reduced to a hydroxyl function in the $\alpha$ position. Moreover, the organism synthesizes a $7 \alpha$-dehydroxylase active on cholic and chenodeoxycholic acids and a $7 \beta$-dehydrogenase active on ursodeoxycholic acid.

Aerotolerance. Pure cultures of $C$. scindens seeded on blood agar plates, left at room temperature under ordinary atmospheric conditions for 4,8 , and $24 \mathrm{~h}$, and then incubated anaerobically at $37^{\circ} \mathrm{C}$ for 2 days form colonies; desmolase activity is retained (1).

\section{DISCUSSION}

Characteristics of the genus Clostridium. According to Smith and Hobbs (20), the genus Clostridium contains anaerobic or microaerophilic rods that produce endospores that usually are wider than the vegetative cells in which they are found. The cells generally are gram positive and may be very active metabolically. Since these characteristics match the features of the desmolase-producing organism, we place it in the genus Clostridium with the name $C$. scindens.

Clostridia metabolizing steroids and bile acids. Of the few Clostridia known to synthesize these specialized enzymes, C. paraputrificum, $C$. innocuum, and Clostridium $\mathrm{J}-1$ strain (Virginia Polytechnic Institute no. 13637) reduce the $\Delta^{4}-3$ keto function of steroid hormones $(2,3)$, whereas $C$. absonum (11) and $C$. perfringens (10) are active on the 7-hydroxy function of bile acids. To these species we may now add $C$. scindens, which synthesizes desmolase, an oxidative enzyme that cleaves the side chain of the D-ring. The mechanism by which the transformation takes place is unknown.

Fimbriae. Another unique feature of $C$. scindens is the presence of filamentous nonflagellar structure, fimbriae. These structures generally have been restricted to gramnegative bacteria (17). Among the gram-positive bacteria 


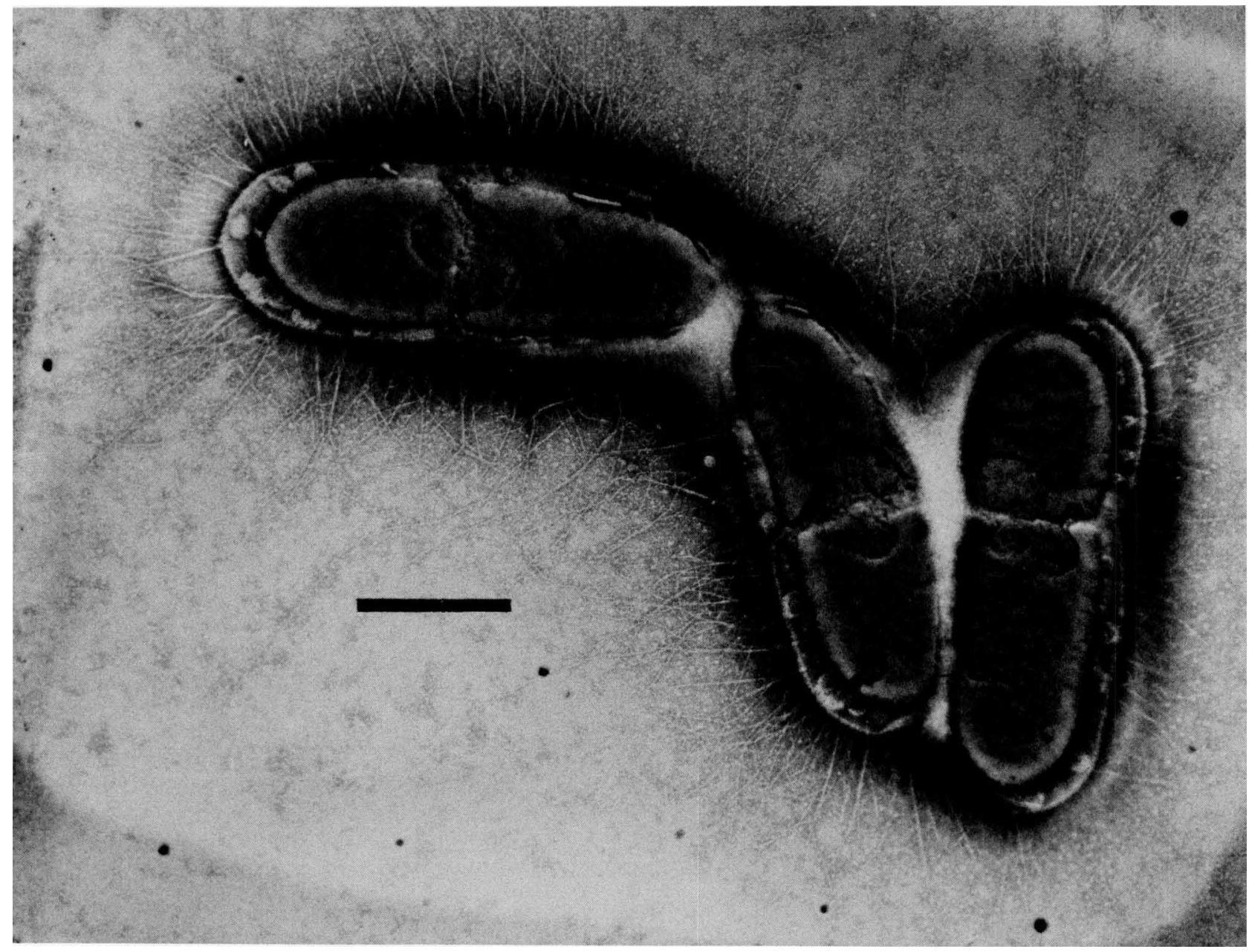

FIG. 1. Electron micrograph of $C$. scindens. Bar, $0.5 \mu \mathrm{m}$; magnification, $\times 40,000$.

only Corynebacterium renale has been reported to possess fimbriae (25). Although broad, ribbon-like appendages have been observed on spores of clostridia (19), the presence of fimbriae has not been reported previously in any other clostridium.

Habitat and distribution of desmolase organisms. Organisms that produce the desmolase enzyme seem to be widely distributed in nature and can be aerobic or anaerobic. The enzyme is synthesized by a number of free-living aerobic soil microorganisms $(15,16,18,21)$. Several of these enzymes cleave not only the side chain of 17-hydroxylated corticoids but also those of 17-nonhydroxylated steroids and sterols. Previous experiments $(5,6)$ and those reported here indicate that desmolase-synthesizing organisms are present in most, if not all, fecal specimens of humans. The concentration of these organisms is about $10^{7} / \mathrm{g}$ of feces, but whether $C$. scindens is the most common desmolase-producing organism inhabiting the human gut is unknown. In view of the fact that at least this strain of $C$. scindens is resistant to most of the conventional antibiotics used in the treatment of anaerobic infection, one might expect that it would occur in abscesses seeded from the intestinal flora. The absence of this organism in such situations, however, may indicate either a low virulence of the species or that other strains of the species are generally more susceptible to these antibiotics than is the strain studied.

\section{ACKNOWLEDGMENTS}

The authors thank J. L. Johnson for determination of guanine plus cytosine content, Ann C. Ridpath for technical assistance and Lillian V. Holdeman for critical review of the manuscript.

This work was supported by grant no. 25763 to St. Luke'sRoosevelt Institute for Health Sciences awarded by the National Cancer Institute, by grant no. 25324 awarded by the National Institute of Arthritis, Diabetes, and Digestive and Kidney Diseases, and in part by project 2025790 from the Commonwealth of Virginia.

\section{LITERATURE CITED}

1. Bokkenheuser, V. D., G. N. Morris, A. E. Ritchie, L. V. Holdeman, and J. Winter. 1984. Biosynthesis of androgen from cortisol by a Clostridium species recovered from human fecal flora. J. Infect. Dis. 149:489-494.

2. Bokkenheuser, V. D., J. Winter, B. I. Cohen, S. O'Rourke, and E. H. Mosbach. 1983. Inactivation of contraceptive steroid hormones by human intestinal clostridia. J. Clin. Microbiol. 18:500-504.

3. Bokkenheuser, V. D., J. Winter, P. Dehazya, O. DeLeon, and W. G. Kelly. 1976. Formation and metabolism of tetrahydrodeoxycorticosterone by human fecal flora. J. Steroid Biochem. 7:837-843.

4. Bokkenheuser, V. D., J. Winter, P. Dehazya, and W. G. Kelly. 1977. Isolation and characterization of human fecal bacteria capable of 21-dehydroxylating corticoids. Appl. Environ. Microbiol. 34:571-575.

5. Cerone-McLernon, A. M., J. Winter, E. H. Mosbach, and V. D. 
Bokkenheuser. 1981. Side-chain cleavage of cortisol by fecal flora. Biochim. Biophys. Acta 666:341-347.

6. Eriksson, H., and J. A. Gustafsson. 1971. Excretion of steroid hormones in adults. Eur. J. Biochem. 18:146-150.

7. Gustafsson, J. A. 1968 . Steroids in germ-free and conventional rats. Identification of $\mathrm{C} 19$ and $\mathrm{C} 21$ steroids in feces from conventional rats. Eur. J. Biochem. 6:248-255.

8. Holdeman, L. V., E. P. Cato, and W. E. C. Moore (ed.). 1977. Anaerobe laboratory manual, 4th ed. Virginia Polytechnic Institute and State University, Blacksburg, Va.

9. Johnson, J. L. 1981. Genetic characterization, p. 450-472. In T. Gerhardt (ed.), Manual of methods of general microbiology. American Society for Microbiology, Washington, D.C.

10. Macdonald, I. A., D. M. Hutchison, T. P. Forest, V. D. Bokkenheuser, J. Winter, and L. V. Holdeman. 1983. Metabolism of primary bile acids by Clostridium perfringens. J. Steroid Biochem. 18:97-104.

11. Macdonald, I. A., and P. D. Roach. 1981. Bile salt induction of $7 \alpha$ and $7 \beta$-hydroxysteroid dehydrogenases in Clostridium absonum. Biochim. Biophys. Acta 665:262-269.

12. Macdonald, I. A., Y. P. Rochon, D. M. Hutchison, and L. V. Holdeman. 1982. Formation of ursodeoxycholic acid from chenodeoxycholic acid by a 7ß-hydroxysteroid dehydrogenaseelaborating Eubacterium aerofaciens strain cocultured with $7 \alpha$-hydroxysteroid dehydrogenase-elaborating organisms. Appl. Environ. Microbiol. 44:1187-1195.

13. Marmur, G., and P. Doty. 1962. Determination of the base composition of deoxyribonucleic acid from its thermal denaturation temperature. J. Mol. Biol. 5:109-118.

14. Nabarro, J. D. N., A. Moxham, G. Walker, and J. D. H. Slater. 1957. Rectal hydrocortisone. Br. Med. J. 2:272-274.

15. Nagassawa, M., M. Bae, G. Tamura, and K. Arima. 1969. Microbial transformation of sterols. II. Cleavage of sterol side chains by microorganisms. Agric. Biol. Chem. 33:1644-1650.

16. Peterson, G. E., R. W. Thoma, D. Perlman, and J. Fried. 1957. Metabolism of progesterone by Cylindrocarpon radicicola and Streptomyces lavendulae. J. Bacteriol. 74:684-688.

17. Ottow, J. C. G. 1975. Ecology, physiology, and genetics of fimbriae and pili. Annu. Rev. Microbiol. 29:79-108.

18. Rahim, M. A., and C. J. Sih. 1966. Mechanisms of steroid oxidation by microorganisms. XI. Enzymatic cleavage of the pregnane side-chain. J. Biol. Chem. 241:3615-3623.

19. Rode, L. J., M. A. Crawford, and M. G. Williams. 1967. Clostridium spores with ribbon-like appendages. J. Bacteriol. 93:1160-1173.

20. Smith, L. D., and G. Hobbs. 1974. Genus III. Clostridium Prazmowski 1880, 23, p. 551-572. In R. E. Buchanan, and N. E. Gibbons, (ed.), Bergey's manual of determinative bacteriology, 8th ed. The Williams \& Wilkins Co., Baltimore.

21. Viola, F., O. Caputo, G. Galliano, L. Delprino, and L. Cattel. 1983. Side chain degradation and microbial reduction of different steroids by Aspergillus aureogulgens. J. Steroid Biochem. 19:1451-1458.

22. Wade, A. P. J., D. H. Slater, A. E. Killie, and M. E. Holliday. 1959. Urinary excretion of 17-keto steroids following rectal infusion of cortisol. J. Clin. Endocrinol. Metab. 19:444-453.

23. Wilkins, T. D., and T. Thiel. 1973. Modified broth-disk method for testing the antibiotic susceptibility of anaerobic bacteria. Antimicrob. Agents Chemother. 3:350-356.

24. Winter, J., G. N. Morris, S. O'Rourke-Locascio, V. D. Bokkenheuser, E. H. Mosbach, B. I. Cohen, and P. B. Hylemon. 1984. Mode of action of steroid desmolase and reductases synthesized by Clostridium "scindens" (formerly Clostridium strain 19). J. Lipid Res. 25:1124-1131.

25. Yanagawa, R., and K. Otsuki. 1970. Some properties of the pili of Corynebacterium renale. J. Bacteriol. 101:1063-1069. 